\title{
Design and Simulation of Novel 3-DOF Spherical Voice Coil Motor
}

\author{
Yi-Hsuan Lin ${ }^{1}$, Chien-Sheng Liu ${ }^{1, *(\mathbb{D})}$ and Chiu-Nung Yeh ${ }^{2}$ \\ 1 Department of Mechanical Engineering, National Cheng Kung University, Tainan 70101, Taiwan; \\ e14066143@gs.ncku.edu.tw \\ 2 International Master Program on Intelligent Manufacturing, National Cheng Kung University, \\ Tainan 70101, Taiwan; nf6091029@gs.ncku.edu.tw \\ * Correspondence: csliu@mail.ncku.edu.tw; Tel.: +886-6-2757575 (ext. 62114)
}

Citation: Lin, Y.-H.; Liu, C.-S.; Yeh, C.-N. Design and Simulation of Novel 3-DOF Spherical Voice Coil Motor. Actuators 2021, 10, 155. https://doi.org/10.3390/act10070155

Academic Editors: Jacek F. Gieras, Shuxiang Dong and Doron Shilo

Received: 11 May 2021

Accepted: 6 July 2021

Published: 7 July 2021

Publisher's Note: MDPI stays neutral with regard to jurisdictional claims in published maps and institutional affiliations.

Copyright: (c) 2021 by the authors. Licensee MDPI, Basel, Switzerland. This article is an open access article distributed under the terms and conditions of the Creative Commons Attribution (CC BY) license (https:// creativecommons.org/licenses/by/ $4.0 /)$.

\begin{abstract}
Multi-DOF motion is realized in the eyes and joints of robots mostly through the combination of multiple one-degree-of-freedom (1-DOF) motors. However, this results in reduced efficiency, a large volume, reduced response speed, and inaccurate positioning. To solve these problems, this study proposes a novel 3-DOF spherical voice coil motor (VCM). In this VCM, 16 coils and a radially oriented ring magnet are used to generate a Lorentz force to achieve motion. In particular, coils for $Z$-axis rotation are sandwiched between the coils for $X$ - and $Y$-axis rotation. Furthermore, the proposed VCM can achieve $360^{\circ}$ rotation about the $Z$-axis. The commercial software ANSYS was used to design and verify the performance of the proposed VCM. Simulation results indicate that this VCM affords improved power efficiency because only a suitable combination of coils, rather than all coils, needs to be powered on. The results demonstrate the feasibility of the proposed 3-DOF spherical VCM.
\end{abstract}

Keywords: three-degree-of-freedom actuator; electromagnetic actuator; spherical actuator; electromagnetic analysis; voice coil motor; voice coil actuator

\section{Introduction}

In recent years, robots have become increasingly popular, and the motors used in the joints of robotic arms have improved gradually. Robot eyes and joints are mostly powered by a combination of multiple one-degree-of-freedom (1-DOF) motors to perform multi-DOF motion. However, this results in reduced efficiency, a large volume, reduced response speed, and inaccurate positioning. To solve these problems, researchers have developed and applied various multi-DOF motors, including permanent magnet motors [1,2], induction motors [3], ultrasonic motors [4], and other types of motors [5,6]. In smartphones, camera modules are used for capturing clear and sharp images. At present, mainstream smartphone camera modules have autofocusing (AF), optical image stabilization (OIS), and optical zoom (OZ) functions [7]. To provide these functions, voice coil motors (VCMs) or voice coil actuators (VCAs) have been widely used because they afford advantages such as a simple structure, compact size, high positioning accuracy, and high power efficiency [8,9]. VCMs with 1- and multi-DOF motion have been developed to realize 1-DOF AF [10-13], 2-DOF OIS [14-18], 2-DOF OZ [7], 3-DOF AF/OIS [19], and 5-DOF AF/OIS [9]. However, these VCMs have a cubic shape, which limits their scope of application.

Considering the aforementioned context, studies have been increasingly focused on the design of spherical VCMs [20-22]. Spherical VCMs can be applied in robot eyes, robot joints, positioning actuators, and medical equipment. Spherical VCMs are divided into two types depending on their electromagnetic design: moving coil type (the coil is the rotor and the magnet is the stator) and moving magnet type (the magnet is the rotor and the coil is the stator). 
Kim et al. [23] proposed a spherical VCM in which the coil was considered one part of the rotor and the magnet was considered one part of the stator. Motion was achieved by the torque produced by the Lorentz force generated from the interaction between the coil and the magnet. A sequential quadratic programming method and the MATLAB optimization toolbox (MathWorks, Natick, MA, USA) were used to optimize the design parameters of the spherical VCM, and 2-DOF motion was achieved. Kim et al. proposed another spherical VCM of this type [24].

Heya et al. proposed another type of spherical VCM [25-27]. In their structure, the coil was considered one part of the stator and the magnet was considered one part of the rotor. Through the appropriate placement of the magnet and yoke, the magnetic field through the coil and the Lorentz force became larger than those in the conventional design. Finally, 3-DOF motion was achieved. However, due to the specific set of magnets used, the movable angle along the Z-axis was only $\pm 5^{\circ}$. Chu et al., Fusayasu et al., and Yang et al. also proposed other spherical VCMs of this type [28-30].

The present study builds upon prior studies of cell phone camera modules by our research group and on existing designs to formulate a new type of 3-DOF spherical VCM for application in robot eyes. This study aims to improve the movable angles of the 3-DOF spherical VCM to mimic the motion of human eyes. The proposed 3-DOF spherical VCM has a compact diameter of $34 \mathrm{~mm}$. Furthermore, it can achieve $360^{\circ}$ rotation along the $Z$-axis. Through a specific design of the electromagnetic structure, its power efficiency can be improved. A finite element method was used to verify the feasibility of the proposed 3-DOF spherical VCM relative to a conventional 3-DOF spherical VCM.

The remainder of this study is organized as follows. Section 2 describes the structure and operating principle of the proposed 3-DOF spherical VCM. Section 3 introduces the parameter settings for simulation and results. Section 4 describes the simulation characterization of the proposed 3-DOF spherical VCM and presents a comparison of its performance with that of the conventional 3-DOF spherical VCM proposed in [26]. Finally, Section 5 concludes the study.

\section{Structure Design}

\subsection{Basic Structure}

Figure 1a,b illustrate the basic structure and components, respectively, of the proposed 3-DOF spherical VCM. The proposed 3-DOF spherical VCM comprises a moving part (i.e., rotor), a fixed part (i.e., stator), and a connector. The rotor comprises a radially oriented ring magnet (Figure 1c) and an inner yoke. The stator comprises 16 coils, an outer yoke, and a fixed base made of a nonmagnetic material. The moving and fixed parts are connected by a spherical bearing (KGLM-03, igus, Cologne, Germany) made of a nonmagnetic material located at the center of the moving part. Of the 16 coils, four, four, and eight coils are used for rotation about the $X_{-}, Y_{-}$, and $Z$-axes, respectively. In addition, the coils are wound around the outer yoke.

We observed the conventional 3-DOF spherical VCM proposed in [26] and found that in some situations, the magnetic field from the radially oriented ring magnet was small in some part of the coils and even changed direction. Therefore, unlike in the conventional structure, we modified the layout of the coils and separated the coils for rotation about the $X$ - and $Y$-axes. The advantage of separated coils is that the power efficiency can be improved by powering only suitable coils instead of all of them. In addition, the coils for $Z$-axis rotation are incorporated into the intermediate layer, that is, they are sandwiched between the coils for rotation along the $X$ - and $Y$-axes. Owing to the use of the radially oriented ring magnet, $360^{\circ}$ rotation can be achieved around the $Z$-axis. Figure 2 illustrates the design parameters of the proposed structure, and Table 1 presents its dimensions. 


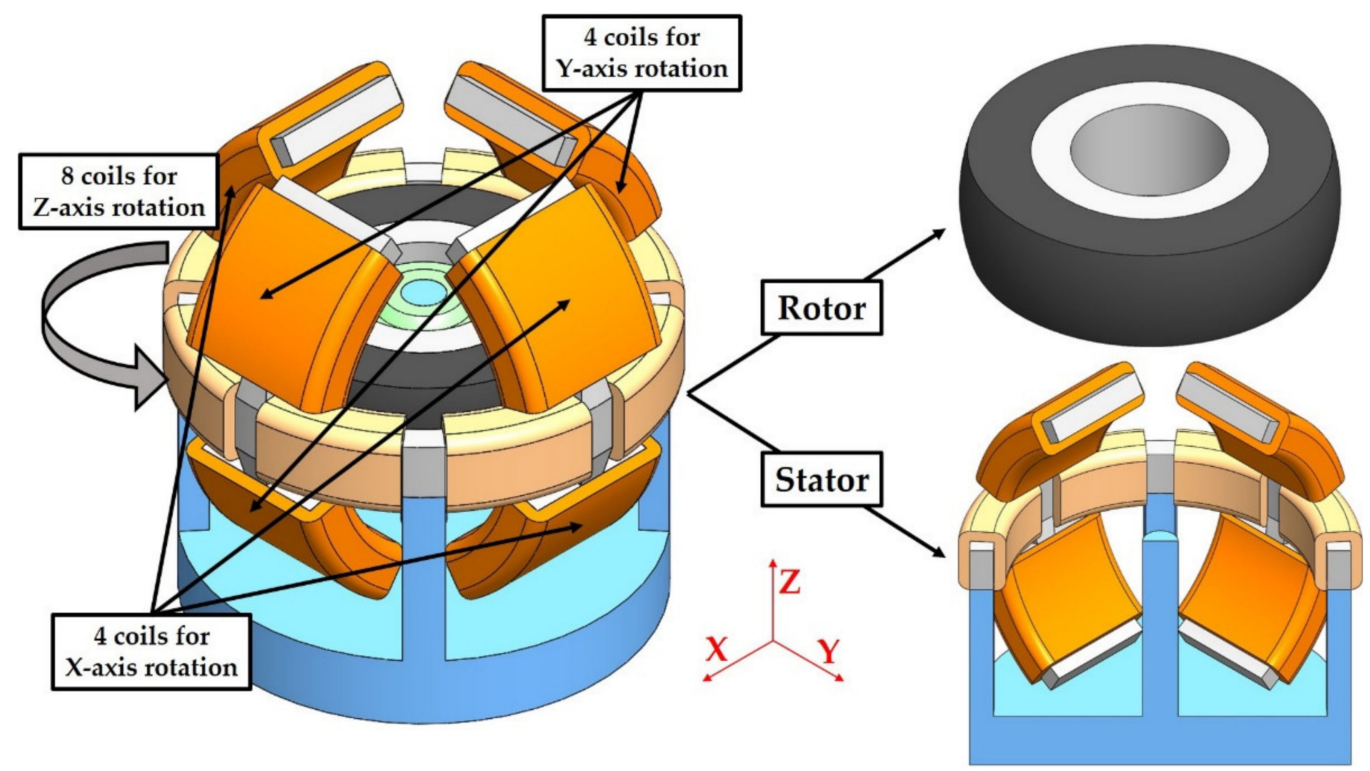

(a)

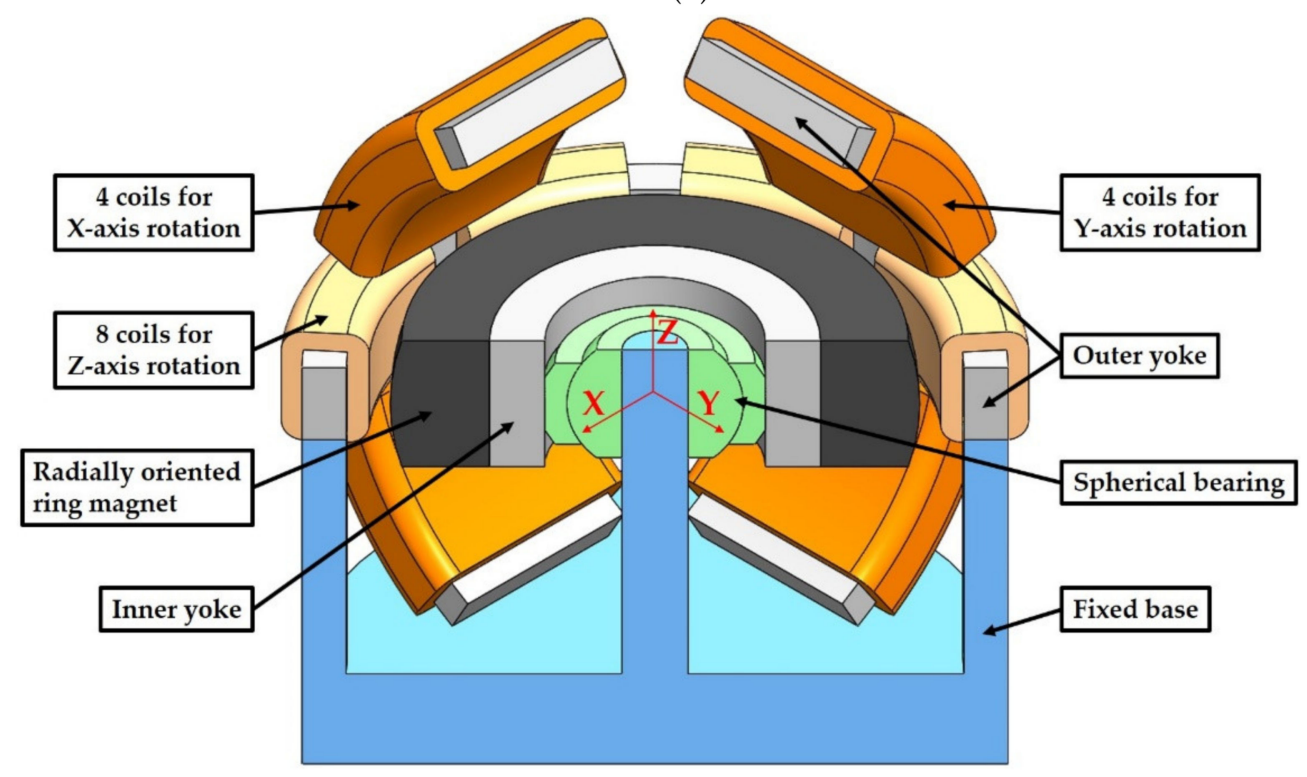

(b)

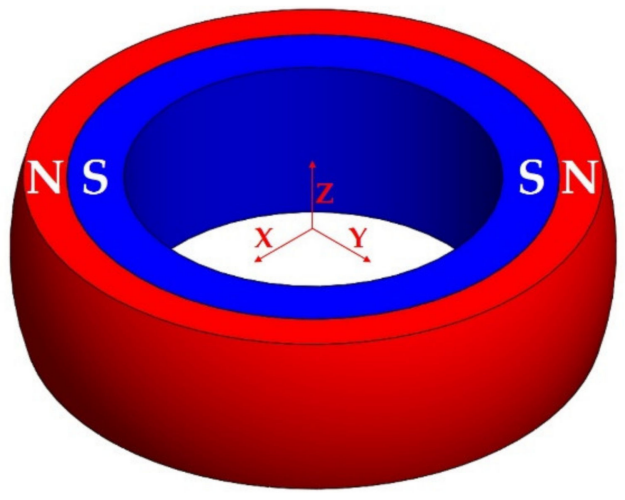

(c)

Figure 1. (a) The basic structure of the proposed 3-DOF spherical VCM; (b) detailed components; (c) radially oriented ring magnet. 


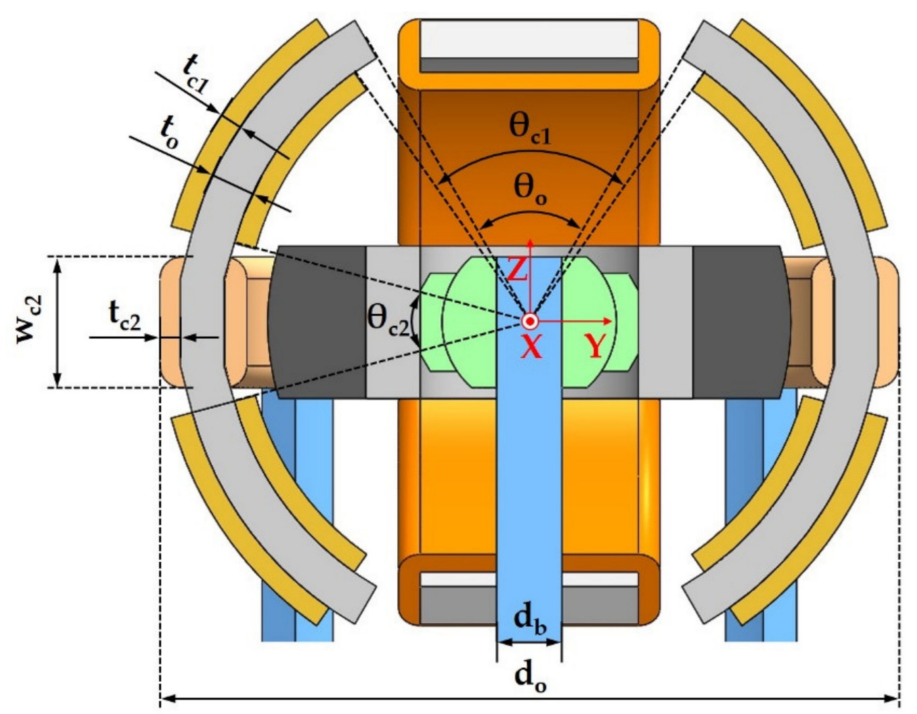

(a)

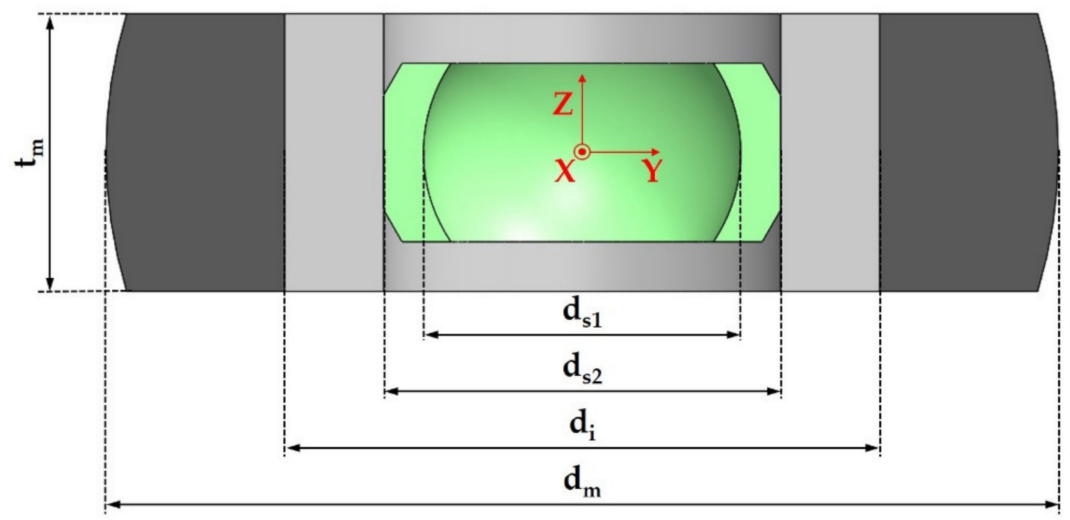

(b)

Figure 2. The design parameters of (a) the structure and (b) the rotor in $Y-Z$ cross section in the proposed 3-DOF spherical VCM.

Table 1. The dimensions of the design parameters.

\begin{tabular}{ccc}
\hline Parameter & Description & Value \\
\hline $\mathrm{d}_{\mathrm{o}}$ & Outermost diameter & $34(\mathrm{~mm})$ \\
$\mathrm{d}_{\mathrm{b}}$ & Fixed base diameter & $3(\mathrm{~mm})$ \\
$\mathrm{t}_{\mathrm{c} 1}$ & Coil thickness for X, Y rotation & $1(\mathrm{~mm})$ \\
$\mathrm{t}_{\mathrm{c} 2}$ & Coil thickness for Z rotation & $1(\mathrm{~mm})$ \\
$\mathrm{w}_{\mathrm{c} 2}$ & Coil width for Z rotation & $6(\mathrm{~mm})$ \\
$\mathrm{t}_{\mathrm{o}}$ & Outer yoke thickness & $2(\mathrm{~mm})$ \\
$\theta_{\mathrm{o}}$ & Outer yoke angle & $60(\mathrm{deg})$ \\
$\theta_{\mathrm{c} 1}$ & Coil angle 1 & $70(\mathrm{deg})$ \\
$\theta_{\mathrm{c} 2}$ & Coil angle 2 & $30(\mathrm{deg})$ \\
$\mathrm{d}_{\mathrm{s} 1}$ & Spherical bearing inner & $8(\mathrm{~mm})$ \\
$\mathrm{d}_{\mathrm{s} 2}$ & diameter & $10(\mathrm{~mm})$ \\
$\mathrm{d}_{\mathrm{i}}$ & Spherical bearing outer & $15(\mathrm{~mm})$ \\
$\mathrm{d}_{\mathrm{m}}$ & diameter & $24(\mathrm{~mm})$ \\
\hline$t_{\mathrm{m}}$ & Inner yoke outer diameter & $7(\mathrm{~mm})$ \\
\hline
\end{tabular}




\subsection{Operating Principle}

The operating principle of the proposed 3-DOF spherical VCM is based on a VCA, as illustrated in Figures 3 and 4. Motion is achieved by the torques produced by the Lorentz force generated from the interaction between the coil and the magnet along the $X_{-}, Y_{-}$-, and $Z$-axes. The direction of rotor tilting is opposite to that of the torque of the coils owing to the Lorentz force. In our study, the ranges of the tilt angles along the $X$ - and $Y$-axes were $\pm 30^{\circ}$ and the range of the rotation angle about the $Z$-axis was $360^{\circ}$.

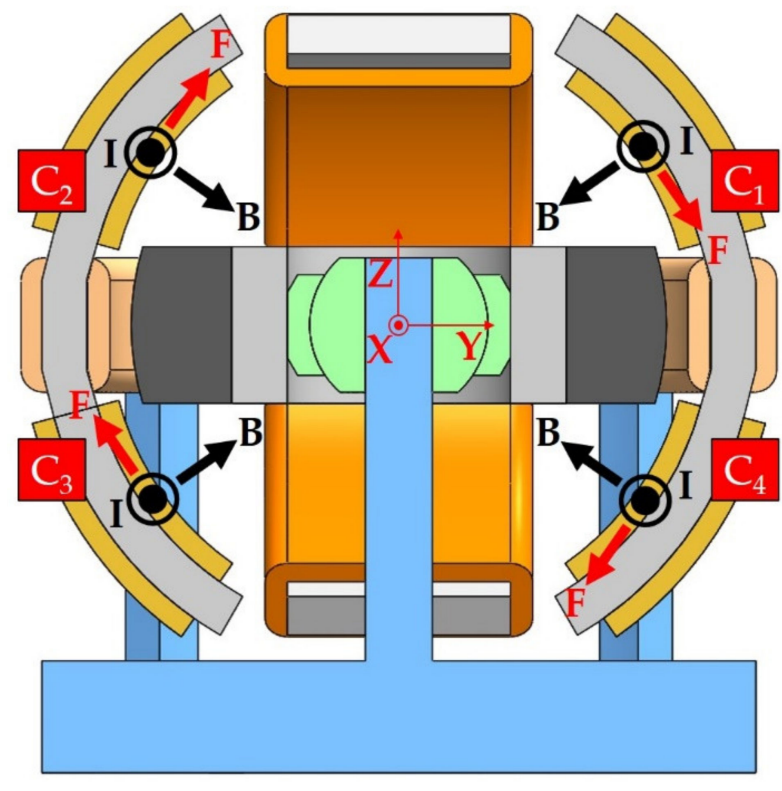

(a)

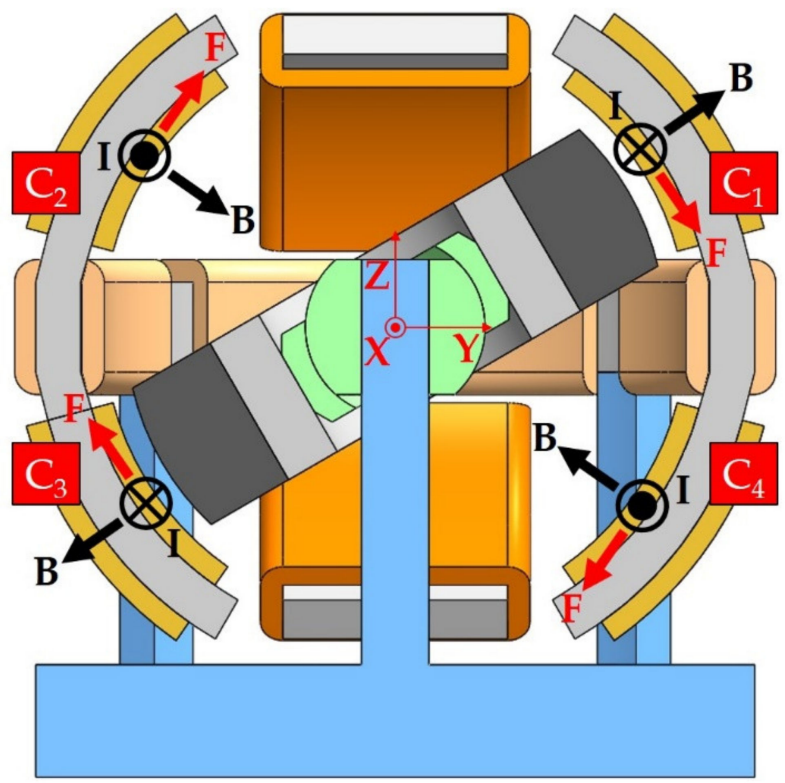

(b)

Figure 3. The operating principle for the rotation about the $X$-axis when the rotor is tilted at (a) $0^{\circ}$ and (b) $30^{\circ}$ along the $X$-axis.

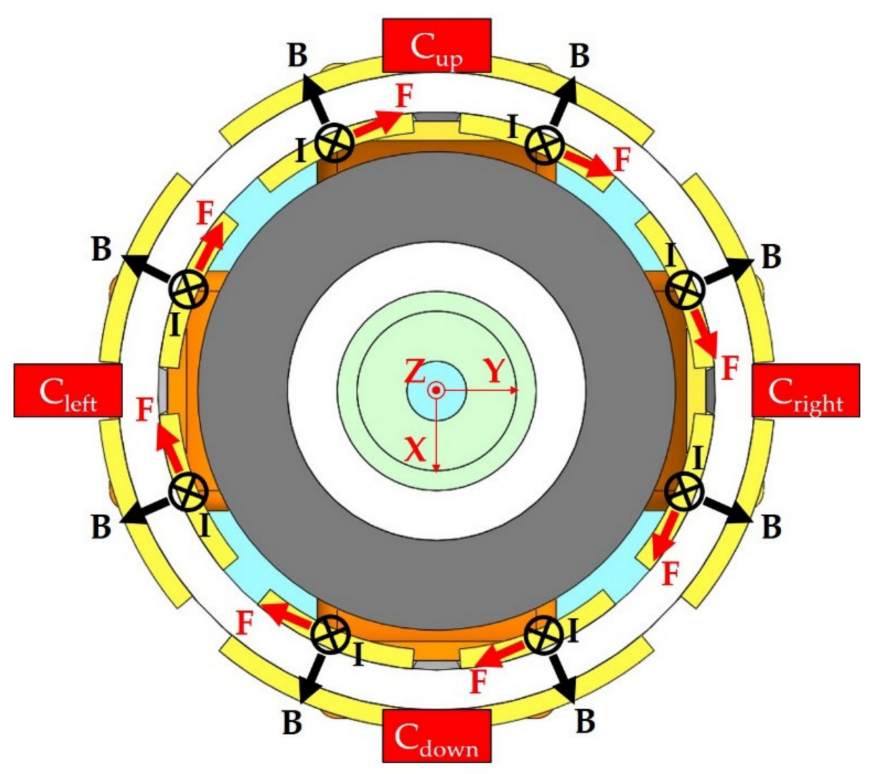

(a)

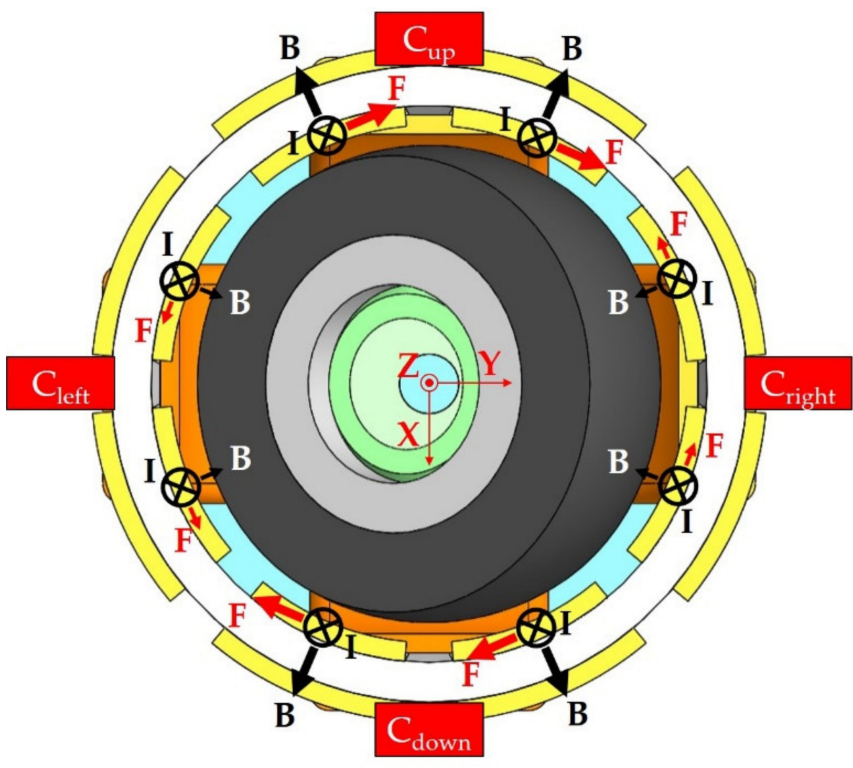

(b)

Figure 4. The operating principle for the rotation about the Z-axis when the rotor is tilted at (a) $0^{\circ}$ and (b) $30^{\circ}$ along the $X$-axis. 
Illustrating the operating principle underlying rotation about the $X$-axis, Figure $3 \mathrm{a}, \mathrm{b}$ indicate the direction of the magnetic field, current, and Lorentz force when the rotor is tilted at $0^{\circ}$ and $30^{\circ}$ along the $X$-axis, respectively. The operating principle of rotation about the $Y$-axis is noted to be similar because the structure of the proposed 3-DOF spherical VCM is symmetric about the Z-axis. Here, we simply discuss the operating principle underlying rotation about the $X$-axis. The direction of the magnetic field through coils $C_{1}$ and $C_{3}$ is seen to change with motion from $0^{\circ}$ to $30^{\circ}$ along the $X$-axis. Therefore, a reverse current must be supplied to maintain the Lorentz force in the same direction. In addition, owing to the closed structure of the magnet, as shown in Figure 1c, the magnetic flux shrinks to the magnet from the top and bottom. Therefore, the magnetic flux through coils $C_{2}$ and $C_{4}$ is not weak, as verified through simulation results (see Section 3). In the proposed structure, when the tilt angle along the $X$-axis is more than $10^{\circ}$, the coils close to the magnet must have a reverse current. By contrast, the current through coils $C_{1}$ and $C_{3}$ and that through coils $\mathrm{C}_{2}$ and $\mathrm{C}_{4}$ flow in opposite directions when the tilt angle along the $X$-axis is more than $10^{\circ}$.

For the operating principle of rotation about the Z-axis, Figure $4 a, b$ indicate the direction of the magnetic field, current, and Lorentz force when the rotor is tilted at $0^{\circ}$ and $30^{\circ}$ about the $X$-axis, respectively. The direction of the magnetic field through coils $C_{\text {left }}$ and $\mathrm{C}_{\text {right }}$ and the direction of the Lorentz force clearly change with motion from $0^{\circ}$ to $30^{\circ}$ along the $X$-axis. With a tilt of $30^{\circ}$ along the $X$-axis, because the magnetic field is too small, coils $C_{\text {left }}$ and $C_{\text {right }}$ are powered off instead of having a reverse current. Therefore, the coils close to the axis of the tilting motion must be prioritized with regard to being powered on. In this case, the $X$-axis is the axis of the tilting motion; therefore, coils $C_{\text {up }}$ and $C_{\text {down }}$ are chosen to be powered on. Owing to the structural design and operating principle, the 16 coils are independent. Figure 5 presents a flowchart illustrating how the proposed 3-DOF spherical VCM is driven.

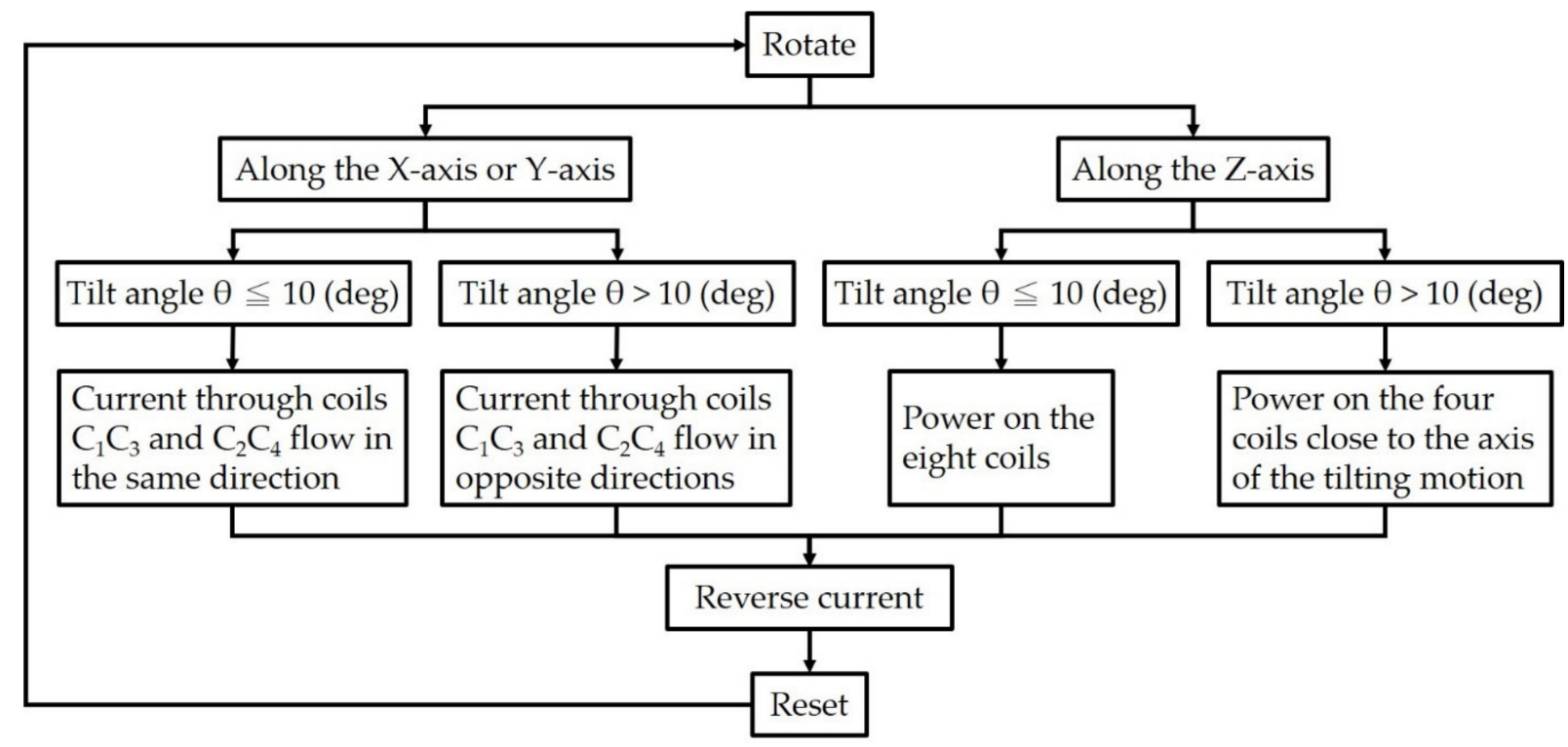

Figure 5. The flowchart to drive the proposed 3-DOF spherical VCM.

\section{Simulation}

\subsection{Parameter Settings for Simulation}

ANSYS commercial software was used to design and verify the performance of the proposed 3-DOF spherical VCM. In the simulation, two scenarios were compared. The first scenario is one of small-angle motion, for which the tilt angles along the $X$-axis are set as $0^{\circ}, 2^{\circ}, 4^{\circ}, 5^{\circ}, 6^{\circ}, 8^{\circ}$, and $10^{\circ}$. The second scenario is one of large-angle motion, for which the tilt angles along the $X$-axis are set as $12^{\circ}, 14^{\circ}, 15^{\circ}, 16^{\circ}, 18^{\circ}, 20^{\circ}, 22^{\circ}, 24^{\circ}, 25^{\circ}, 26^{\circ}, 28^{\circ}$, and $30^{\circ}$. 
Figure $6 \mathrm{a}, \mathrm{b}$ present 3D mesh models of the proposed 3-DOF spherical VCM for smalland large-angle motion, respectively. The other parameter settings in ANSYS software are as follows. The materials of the radially oriented ring magnet, coils, and yoke are $\mathrm{NdFe} 35$, copper, and steel-1008, respectively. The total currents through the cross section of the coils for rotation about the $X_{-}, Y_{-}$, and $Z$-axes are 500, 500, and 450 (A-turns), respectively. Consider the coils for rotation about the $X$-axis as an example; the measurement of a total current of 500 (A-turns) indicates a coil of 500 turns and a current of $1 \mathrm{~A}$.

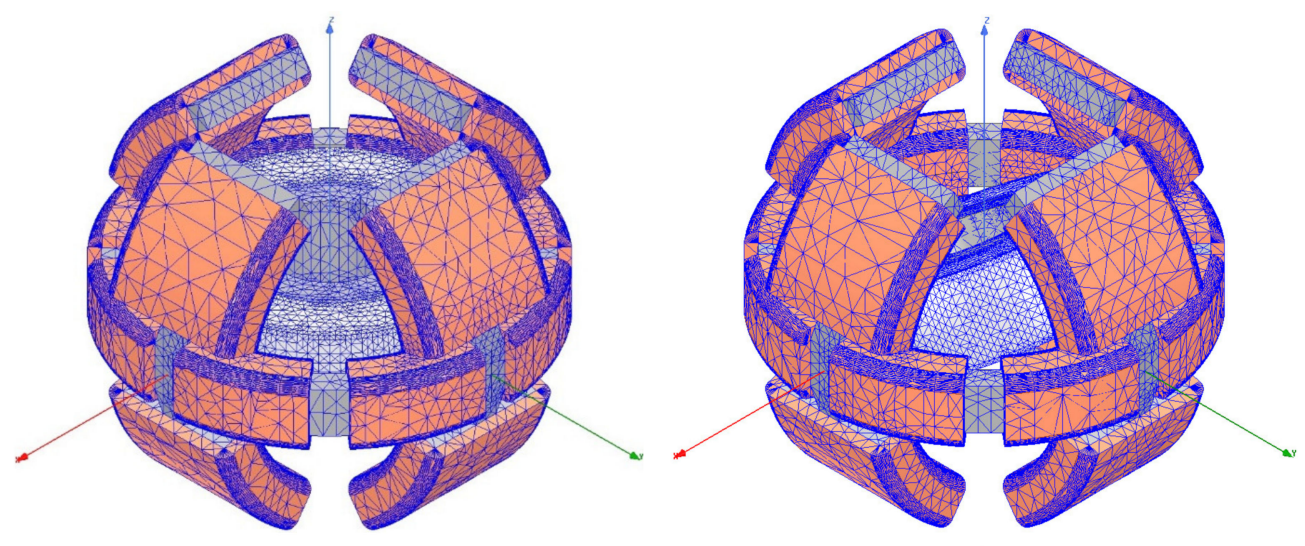

(a) (b)

Figure 6. The 3D mesh model of the proposed 3-DOF spherical VCM for (a) small-angle motion and (b) large-angle motion.

\subsection{Plan of the Simulations}

Figure 7 illustrates how the simulations of the proposed 3-DOF spherical VCM proceeded. The models are completed in SolidWorks commercial software and then imported into ANSYS for simulation. After the simulation parameters were set, two scenarios must be simulated to investigate the intersection of the torque, which yield the tilt angle for which reverse current occurs. Finally, the simulation results during small- and large-angle motion are plotted and discussed.

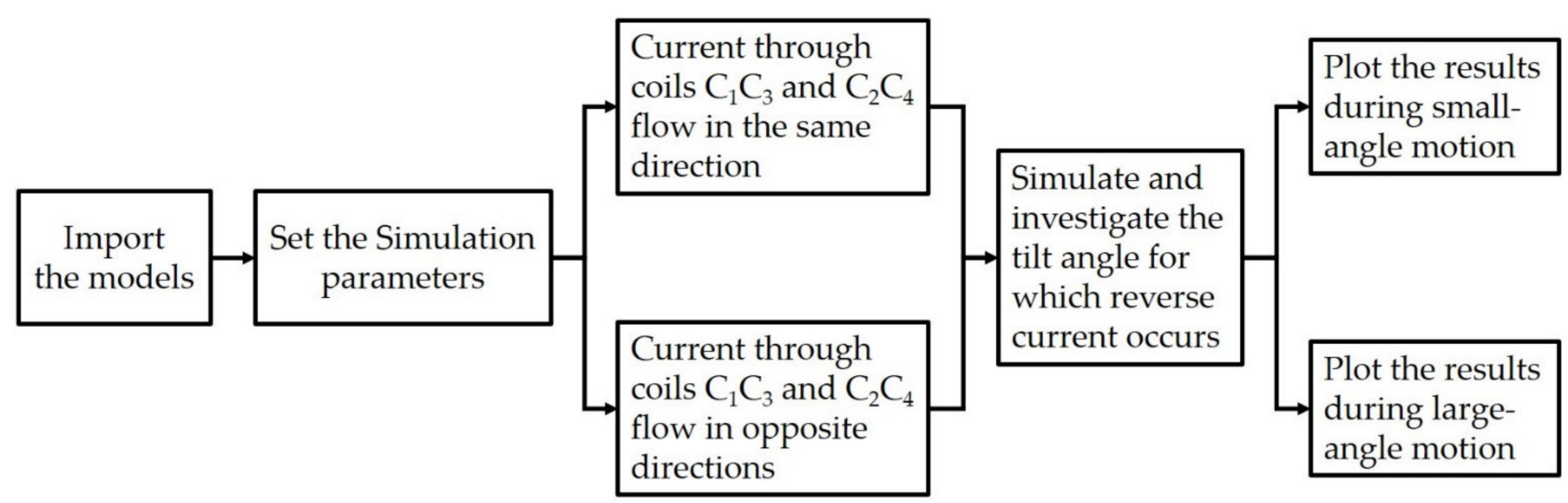

Figure 7. The plan of the simulations of the proposed 3-DOF spherical VCM.

\subsection{Simulation Results}

Figures 8 and 9 illustrate the simulation results of the magnetic field distribution for rotation about the $X$ - and Z-axes, respectively, when the rotor is tilted at $0^{\circ}$ and $30^{\circ}$ along the $X$-axis. Videos S1-S4 for Figures 8 and 9 are provided in the Supplementary Materials. 


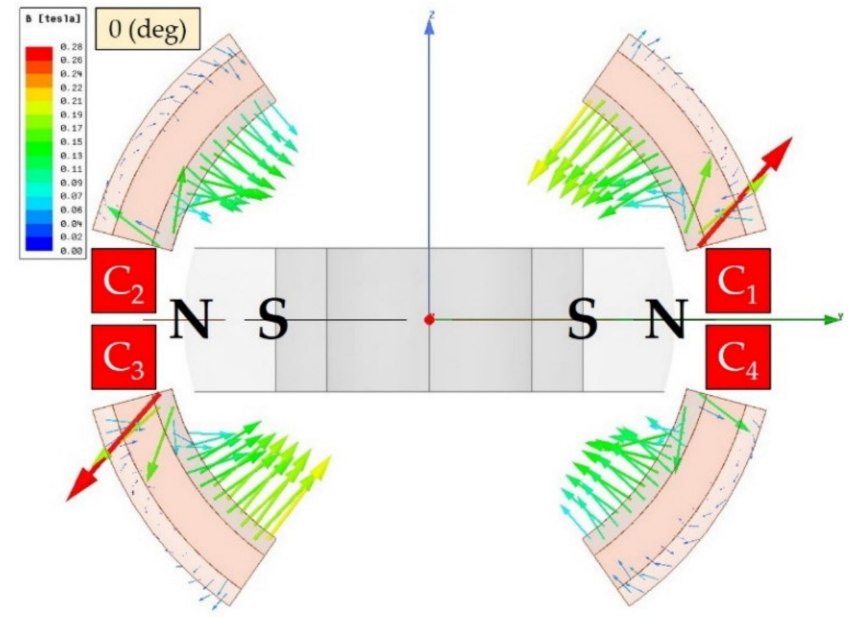

(a)

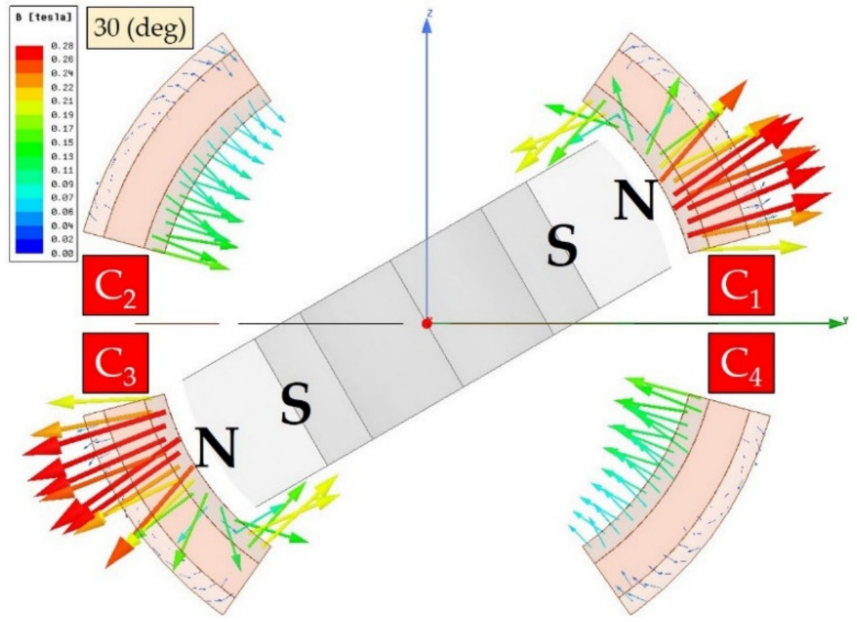

(b)

Figure 8. The magnetic field distribution for the rotation about the $X$-axis when the rotor is tilted at (a) $0^{\circ}$ and (b) $30^{\circ}$ along the $X$-axis.

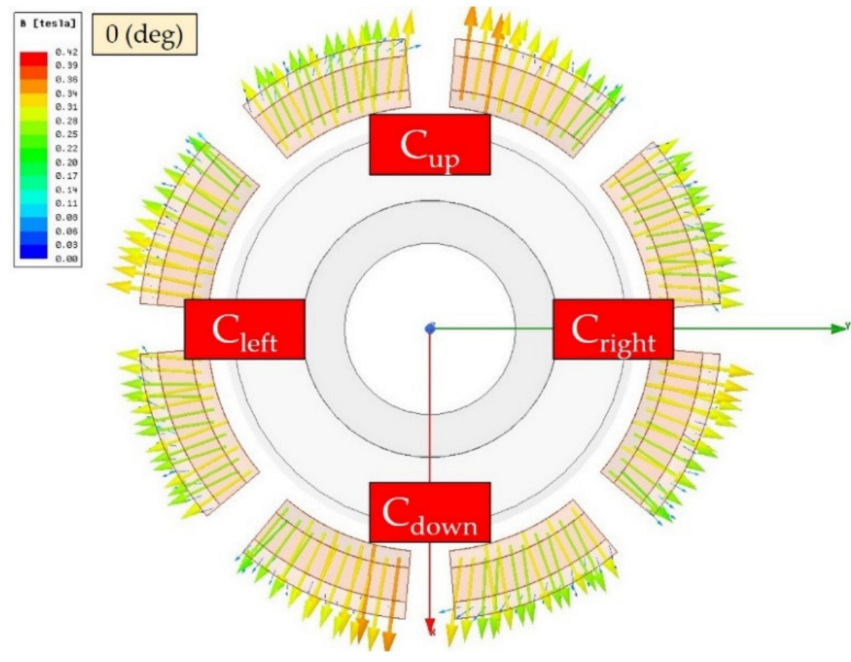

(a)

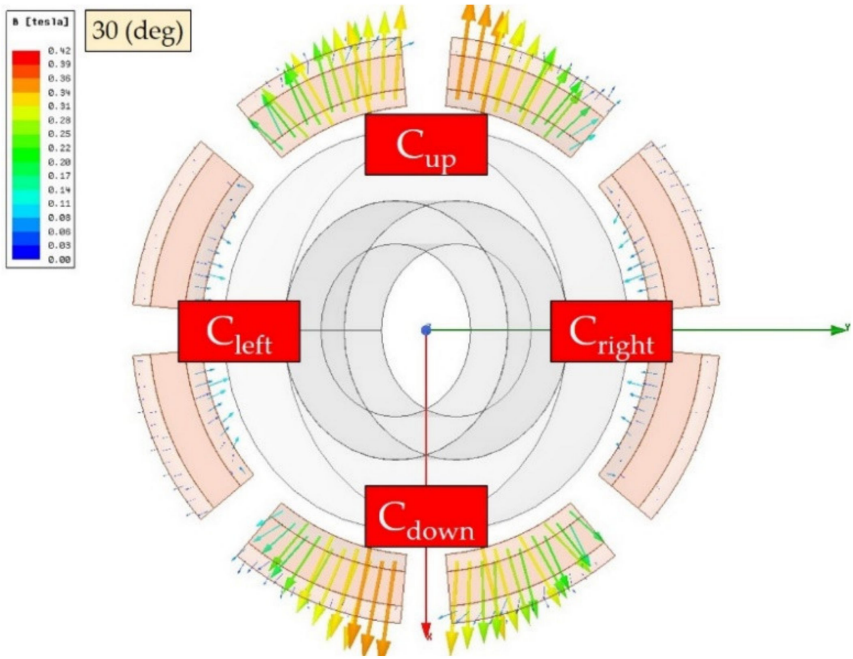

(b)

Figure 9. The magnetic field distribution for the rotation about the Z-axis when the rotor is tilted at (a) $0^{\circ}$ and (b) $30^{\circ}$ along the $X$-axis.

Figure 10a,b indicate the change in torque for the $X$-axis (or $Y$-axis) and $Z$-axis with respect to the tilt angle along the $X$-axis, respectively. These results are listed in Tables 2 and 3. Torque-13, Torque-24, Torque-LR, Torque-UD, and Torque-all indicate the torque generated from coils $C_{1}$ and $C_{3}, C_{2}$ and $C_{4}, C_{\text {left }}$ and $C_{\text {right }}, C_{\text {up }}$ and $C_{\text {down }}$, and all coils, respectively. Thus, both Torque-all values are key performance indexes for the proposed 3-DOF spherical VCM. 


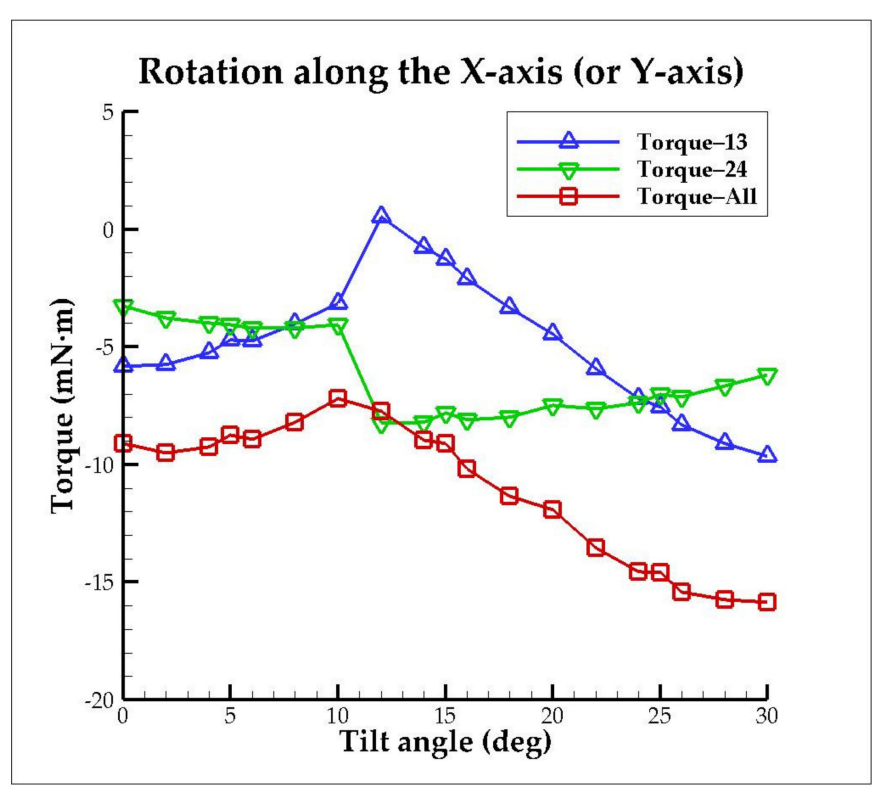

(a)

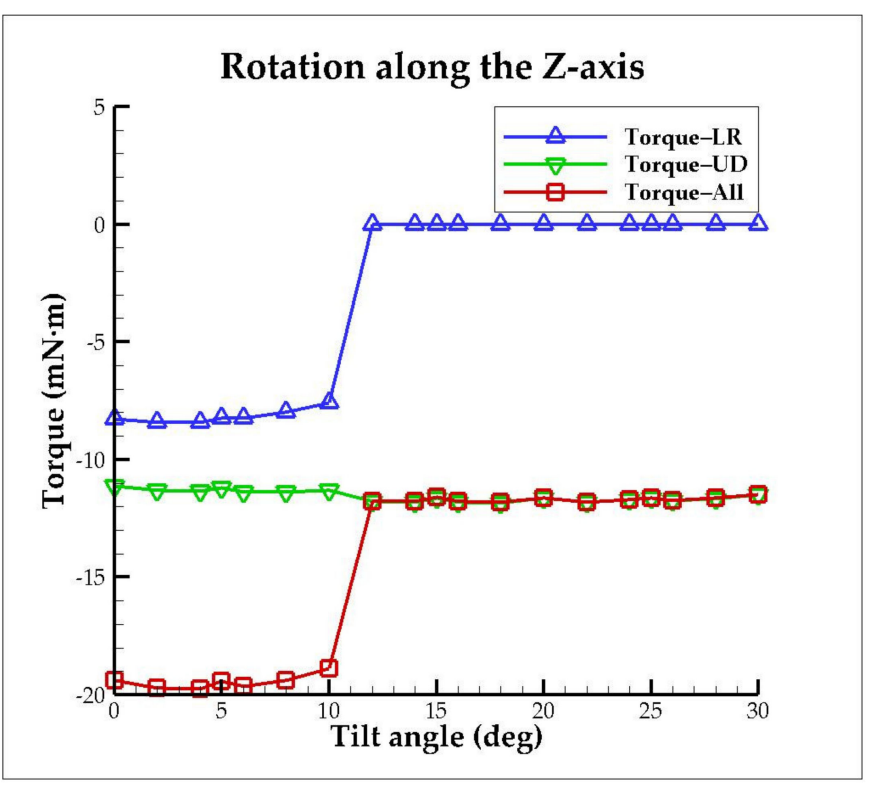

(b)

Figure 10. The change in torque with respect to the tilt angle along the $X$-axis for the (a) $X$-axis (or $Y$-axis) and (b) $Z$-axis.

Table 2. The values of the torque with respect to the tilt angle along the $X$-axis for the $X$-axis (or $Y$-axis).

\begin{tabular}{cccc}
\hline $\begin{array}{c}\text { Tilt Angle } \\
\text { (Deg) }\end{array}$ & $\begin{array}{c}\text { Torque-13 }(\mathbf{m N} \cdot \mathbf{m}) \\
\text { (Coils } \mathbf{C}_{\mathbf{1}} \text { and } \mathbf{C}_{\mathbf{3}} \text { ) }\end{array}$ & $\begin{array}{c}\text { Torque-24 }(\mathbf{m N} \cdot \mathbf{m}) \\
\text { (Coils } \mathbf{C}_{\mathbf{2}} \text { and } \mathbf{C}_{\mathbf{4}} \text { ) }\end{array}$ & $\begin{array}{c}\text { Torque-All }(\mathbf{m N} \cdot \mathbf{m}) \\
\text { (All Coils) }\end{array}$ \\
\hline 0 & -5.83 & -3.26 & -9.09 \\
5 & -4.69 & -4.05 & -8.74 \\
10 & -3.14 & -4.06 & -7.20 \\
12 & 0.53 & -8.24 & -7.72 \\
15 & -1.28 & -7.81 & -9.09 \\
20 & -4.44 & -7.48 & -11.93 \\
25 & -7.57 & -7.02 & -14.59 \\
30 & -9.66 & -6.20 & -15.85 \\
\hline
\end{tabular}

Table 3. The values of the torque with respect to the tilt angle along the $X$-axis for the $Z$-axis.

\begin{tabular}{cccc}
\hline $\begin{array}{c}\text { Tilt Angle } \\
\text { (Deg) }\end{array}$ & $\begin{array}{c}\text { Torque-LR }(\mathbf{m N} \cdot \mathbf{m}) \\
\left(\text { Coils } \mathbf{C}_{\text {left }} \text { and } \mathbf{C}_{\text {right }}\right)\end{array}$ & $\begin{array}{c}\text { Torque-UD }(\mathbf{m N} \cdot \mathbf{m}) \\
\left(\text { Coils } \mathbf{C}_{\text {up }} \text { and } \mathbf{C}_{\text {down }} \text { ) }\right.\end{array}$ & $\begin{array}{c}\text { Torque-All }(\mathbf{m N} \mathbf{m}) \\
\text { (All Coils) }\end{array}$ \\
\hline 0 & -8.26 & -11.14 & -19.40 \\
5 & -8.25 & -11.18 & -19.43 \\
10 & -7.58 & -11.30 & -18.89 \\
12 & 0 & -11.79 & -11.79 \\
15 & 0 & -11.63 & -11.63 \\
20 & 0 & -11.63 & -11.63 \\
25 & 0 & -11.64 & -11.64 \\
30 & 0 & -11.49 & -11.49 \\
\hline
\end{tabular}

\section{Discussion}

As illustrated in Figure 8, the direction of the magnetic field through coils $C_{1}$ and $C_{3}$ changes during large-angle motion along the $X$-axis. Therefore, a reverse current must be supplied to coils $C_{1}$ and $C_{3}$. As shown in Figure 9, the magnitude of the magnetic field through coils $C_{\text {left }}$ and $C_{\text {right }}$ decreases when the rotor is in large-angle motion. Because the $X$-axis is the axis of the tilting motion, coils $C_{\text {left }}$ and $C_{\text {right }}$ are not powered on. The Lorentz force is defined as the force generated from a coil in a magnetic field. Owing to the 
definition of the Lorentz force and the constant current, the results are focused only on the magnetic field through the coils.

Figure 10a and Table 2 indicate that Torque-all for the $X$-axis (or $Y$-axis) increases due to the reverse current. In the previous discussion, the magnetic field distribution was generated only from the magnet, which mostly affects the torque of the proposed 3-DOF spherical VCM. Notably, another magnetic field is generated from the energized coils according to Ampère's circuital law, as shown in Figure 11. When coils $C_{1}$ and $C_{3}$ have a reverse current, the direction of the magnetic field due to Ampère's circuital law in both coils $C_{2}$ and $C_{3}$ and coils $C_{1}$ and $C_{4}$ points toward the middle of the structure (see Figure 11b). Consequently, Torque-24 also increases owing to the reverse current and increased magnetic flux through coils $\mathrm{C}_{2}$ and $\mathrm{C}_{4}$.

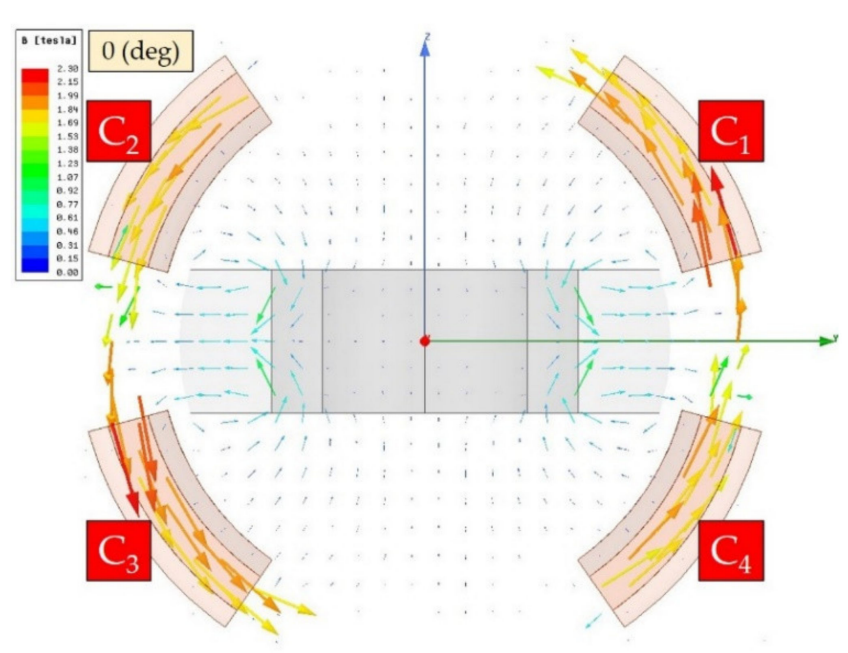

(a)

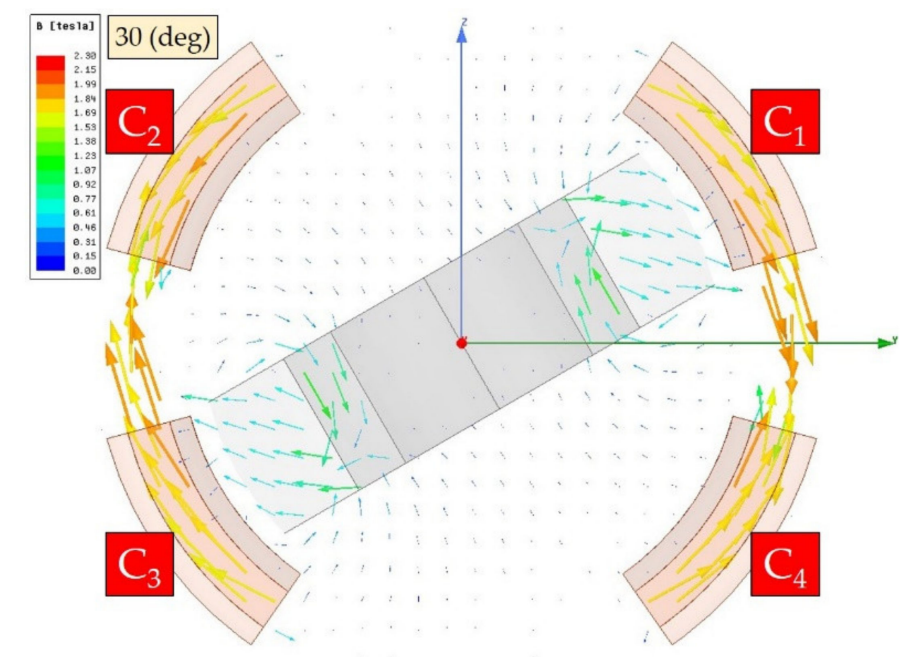

(b)

Figure 11. The magnetic field distribution due to Ampère's circuital law for the rotation about the $X$-axis when the rotor is tilted at (a) $0^{\circ}$ and (b) $30^{\circ}$ along the $X$-axis.

Figure $10 \mathrm{~b}$ and Table 3 indicate that Torque-all for the Z-axis decreases during largeangle motion because only half the coils (i.e., coils $C_{\text {up }}$ and $C_{\text {down }}$ ) need to be powered on. The equation for power consumption is expressed as

$$
\mathrm{P}=\mathrm{IV}=\mathrm{I}^{2} \mathrm{R}
$$

when the rotor rotates around the Z-axis during small-angle motion, the total power consumption, $\mathrm{P}_{\text {all }}$, is expressed as

$$
\mathrm{P}_{\text {all }}=\mathrm{I}^{2}{ }_{\text {up }} \mathrm{R}+\mathrm{I}^{2}{ }_{\text {down }} \mathrm{R}+\mathrm{I}^{2}{ }_{\text {left }} \mathrm{R}+\mathrm{I}_{\text {right }}^{2} \mathrm{R}
$$

where $I_{\text {up }}, I_{\text {down }}, I_{\text {left }}$, and $I_{\text {right }}$ are the currents of $C_{\text {up }}, C_{\text {down }}, C_{\text {left }}$, and $C_{\text {right }}$, respectively, and $\mathrm{R}$ is the resistance of the coils. Here, the currents of all coils are the same. Therefore, Equation (2) can be rewritten as

$$
\mathrm{P}_{\text {all }}=4 \mathrm{I}^{2} \mathrm{R}
$$

when the rotor rotates around the Z-axis during large-angle motion, the total power consumption, $\mathrm{P}_{\text {all }}$, is expressed as

$$
\mathrm{P}_{\text {all }}{ }^{\prime}=\mathrm{I}^{2}{ }_{\text {up }} \mathrm{R}+\mathrm{I}_{\text {down }}^{2} \mathrm{R}=2 \mathrm{I}^{2} \mathrm{R}
$$

notably, when the rotor rotates around the $\mathrm{Z}$-axis, $\mathrm{P}_{\text {all }}{ }^{\prime}$ during large-angle motion is just half that during small-angle motion. Consequently, the power efficiency is improved. The proposed improved method is expected to provide more uniform torque at the same power 
consumption, that is, $I_{u p}$ and $I_{\text {down }}$ at $\sqrt{ } 2$ times the current are supplied during large-angle motion. Table 4 lists the corresponding values of the improved torque with respect to the tilt angle along the $X$-axis. The improved Torque-all is clearly better than that of the original method during large-angle motion.

Table 4. The values of the improved torque with respect to the tilt angle along the $X$-axis for the Z-axis.

\begin{tabular}{|c|c|c|c|}
\hline $\begin{array}{l}\text { Tilt Angle } \\
\text { (Deg) }\end{array}$ & $\begin{array}{l}\text { Torque-LR }(\mathrm{mN} \cdot \mathrm{m}) \\
\left(\text { Coils } \mathrm{C}_{\text {left }} \text { and } \mathrm{C}_{\text {right }}\right)\end{array}$ & $\begin{array}{l}\text { Torque-UD }(\mathrm{mN} \cdot \mathrm{m}) \\
\left(\text { Coils } \mathrm{C}_{\text {up }} \text { and } \mathrm{C}_{\text {down }}\right)\end{array}$ & $\begin{array}{l}\text { Torque-All }(\mathrm{mN} \cdot \mathrm{m}) \\
\text { (All Coils) }\end{array}$ \\
\hline 0 & -8.26 & -11.14 & -19.40 \\
\hline 5 & -8.25 & -11.18 & -19.43 \\
\hline 10 & -7.58 & -11.30 & -18.89 \\
\hline 12 & 0 & -14.35 & -14.35 \\
\hline 15 & 0 & -14.24 & -14.24 \\
\hline 20 & 0 & -14.14 & -14.14 \\
\hline 25 & 0 & -14.20 & -14.20 \\
\hline 30 & 0 & -14.08 & -14.08 \\
\hline
\end{tabular}

From the simulation characterization of the proposed 3-DOF spherical VCM, the movable angle of the $X$ - and $Y$-axes is $\pm 30^{\circ}$ and that of the $Z$-axis is $360^{\circ}$. For the conventional 3 -DOF spherical VCM proposed in [26], the movable angle of the $X$ - and $Y$-axes is $\pm 25^{\circ}$ and that of the Z-axis is $\pm 5^{\circ}$. Consequently, the proposed 3-DOF spherical VCM performs better than the conventional 3-DOF spherical VCM proposed in [26].

In summary, the simulation results indicate that the magnetic field distribution and output torque match the operating principle proposed in Section 2. Furthermore, Toqueall for the $X-, Y-$, and $Z$-axes is improved. The simulation results verify the excellent performance of the proposed compact 3-DOF spherical VCM, and it thus represents a suitable solution for multi-DOF spherical VCM applications in robot eyes, robot joints, positioning actuators, and medical equipment. In particular, robot eyes do not require an overly large torque to drive. The proposed VCM enables larger tilt angles along the $X$ - and $Y$-axes and even a rotation angle of $360^{\circ}$ around the $Z$-axis. Therefore, it exhibits great promise for application to robot eyes.

\section{Conclusions}

This study proposes a 3-DOF spherical VCM and presents its structure, operating principle, and simulation. The separated coils in the proposed structure enable more combinations of powered or unpowered coils. This not only improves the power efficiency but also provides more space to place coils for $Z$-axis rotation. In addition, the proposed motor has a large tilt angle of $\pm 30^{\circ}$ along the $X$ - and $Y$-axes and even achieves a rotation angle of $360^{\circ}$ around the Z-axis. These features make it more promising for various applications. In the future, the design of this VCM will be optimized and a laboratory prototype will be manufactured to evaluate its dynamic performance.

\section{Patents}

The innovation and proposed structure resulting from the work reported in this article are applying for Taiwan and USA patents.

Supplementary Materials: The following are available online at https:/ / www.mdpi.com/article/10 $.3390 /$ act10070155/s1, Video S1: The magnetic field distribution for the rotation about the X-axis when the rotor is in small-angle motion. Video S2: The magnetic field distribution for the rotation about the $X$-axis when the rotor is in large-angle motion. Video S3: The magnetic field distribution for the rotation about the Z-axis when the rotor is in small-angle motion. Video S4: The magnetic field distribution for the rotation about the $Z$-axis when the rotor is in large-angle motion. 
Author Contributions: Conceptualization, Y.-H.L. and C.-S.L.; formal analysis, Y.-H.L. and C.-N.Y.; methodology, Y.-H.L. and C.-S.L.; validation, Y.-H.L.; investigation, Y.-H.L. and C.-S.L.; writingoriginal draft preparation, Y.-H.L.; writing—review and editing, C.-S.L.; software, C.-N.Y.; supervision, C.-S.L.; project administration, C.-S.L.; funding acquisition, C.-S.L. All authors have read and agreed to the published version of the manuscript.

Funding: This research was funded by the Ministry of Science and Technology of Taiwan, grant numbers MOST 105-2221-E-194-013-MY5, 106-2628-E-194-001-MY3, and 108-2218-E-002-071.

Acknowledgments: Ansys Inc. is thanked for providing ANSYS academic partner program.

Conflicts of Interest: The authors declare no conflict of interest.

\section{References}

1. Gan, L.; Pei, Y.; Chai, F. Tilting torque calculation of a novel tiered type permanent magnet spherical motor. IEEE Trans. Ind. Electron. 2019, 67, 421-431. [CrossRef]

2. Tao, W.; Li, G.; Ju, L.; Zhou, R.; Hu, C. Design and analysis of a novel spherical motor based on the principle of reluctance. In Proceedings of the 2018 IEEE International Power Electronics and Application Conference and Exposition (PEAC), Shenzhen, China, 4-7 November 2018; pp. 1-6.

3. Yan, L.; Duan, Z.; Zhang, Q.; Qiao, H.; Gerada, C. Development and structure of multi-dof spherical induction motor. In Proceedings of the 2018 13th IEEE Conference on Industrial Electronics and Applications (ICIEA), Wuhan, China, 31 May-2 June 2018; pp. 2831-2835.

4. Mizuno, A.; Oikawa, K.; Aoyagi, M.; Kajiwara, H.; Tamura, H.; Takano, T. Examination of high-torque sandwich-type spherical ultrasonic motor using with high-power multimode annular vibrating stator. Actuators 2018, 7, 8. [CrossRef]

5. Mansour, N.A.; Shin, B.; Ryu, B.; Kim, Y. Development of a Novel Miniaturized Electromagnetic Actuator for a Modular Serial Manipulator. Actuators 2021, 10, 14. [CrossRef]

6. Diep, B.T.; Nguyen, N.D.; Tran, T.T.; Nguyen, Q.H. Design and Experimental Validation of a 3-DOF Force Feedback System Featuring Spherical Manipulator and Magnetorheological Actuators. Actuators 2020, 9, 19. [CrossRef]

7. Chang, Y.H.; Hu, C.C.; Hsieh, C.L.; Liu, C.S. Design of VCM actuator for optical zooming smartphone cameras. Microsyst. Technol. 2019, 25, 277-281. [CrossRef]

8. Kwon, T.H.; Ro, J.S. Analysis and Optimal Design of a Novel Actuator System for a Camera Module. IEEE Access 2020, 9 , 3441-3450. [CrossRef]

9. Hsieh, C.L.; Liu, C.S.; Cheng, C.C. Design of a 5 degree of freedom-voice coil motor actuator for smartphone camera modules. Sens. Actuators A Phys. 2020, 309, 112014. [CrossRef]

10. Chung, M.J. Development of compact auto focus actuator for camera phone by applying new electromagnetic configuration. In Proceedings of the Optomechatronic Actuators and Manipulation, Sapporo, Japan, 5-7 December 2005; Volume 6048, p. 60480J.

11. Yu, H.C.; Lee, T.Y.; Wang, S.J.; Lai, M.L.; Ju, J.J.; Huang, D.R.; Lin, S.K. Design of a voice coil motor used in the focusing system of a digital video camera. IEEE Trans. Magn. 2005, 41, 3979-3981.

12. Chiu, C.W.; Chao, P.C.P.; Wu, D.Y. Optimal design of magnetically actuated optical image stabilizer mechanism for cameras in mobile phones via genetic algorithm. IEEE Trans. Magn. 2007, 43, 2582-2584. [CrossRef]

13. Lai, L.K.; Tsai, C.L.; Liu, T.S. Design of compact linear electromagnetic actuator for auto-focusing in phone camera. IEEE Trans. Magn. 2011, 47, 4740-4744. [CrossRef]

14. Song, M.G.; Hur, Y.J.; Park, N.C.; Park, K.S.; Park, Y.P.; Lim, S.C.; Park, J.H. Design of a voice-coil actuator for optical image stabilization based on genetic algorithm. IEEE Trans. Magn. 2009, 45, 4558-4561. [CrossRef]

15. Song, M.G.; Baek, H.W.; Park, N.C.; Park, K.S.; Yoon, T.; Park, Y.P.; Lim, S.C. Development of small sized actuator with compliant mechanism for optical image stabilization. IEEE Trans. Magn. 2010, 46, 2369-2372. [CrossRef]

16. Hsieh, C.L.; Chang, Y.H.; Chen, Y.T.; Liu, C.S. Design of VCM actuator with L-shape coil for smartphone cameras. Microsyst. Technol. 2018, 24, 1033-1040. [CrossRef]

17. Chiu, C.W.; Chao, P.C.P.; Kao, N.Y.Y.; Young, F.K. Optimal design and experimental verification of a magnetically actuated optical image stabilization system for cameras in mobile phones. J. Appl. Phys. 2008, 103, 07F136. [CrossRef]

18. Chao, P.C.P.; Chen, Y.H.; Chiu, C.W.; Tsai, M.Y.; Chang, J.Y.; Lin, S.K. A new two-DOF rotational optical image stabilizer. Microsyst. Technol. 2011, 17, 1037-1049. [CrossRef]

19. Chang, Y.H.; Lu, C.J.; Liu, C.S.; Liu, D.S.; Chen, S.H.; Liao, T.W.; Peng, W.Y.; Lin, C.H. Design of miniaturized optical image stabilization and autofocusing camera module for cellphones. Sens. Mater. 2017, 29, 989-995.

20. Xu, J.; Wang, Q.; Li, G.; Zhou, R.; Wen, Y.; Ju, L.; Zhou, S. Sensorless Posture Detection of Reluctance Spherical Motor Based on Mutual Inductance Voltage. Appl. Sci. 2021, 11, 3515. [CrossRef]

21. Cho, S.; Lim, J.S.; Oh, Y.J.; Jeong, G.; Kang, D.W.; Lee, J. A Study on Output Characteristics of the Spherical Multi-DOF Motor According to the Number of Phases and Pole Pitch Angles. IEEE Trans. Magn. 2018, 54, 8205005. [CrossRef]

22. Sakaidani, Y.; Hirata, K.; Maeda, S.; Niguchi, N. Feedback control of the 2-DOF actuator specialized for 2-axes rotation. IEEE Trans. Magn. 2013, 49, 2245-2248. [CrossRef] 
23. Kim, H.; Kim, H.; Ahn, D.; Gweon, D. Design of a new type of spherical voice coil actuator. Sens. Actuators A Phys. 2013, 203, 181-188. [CrossRef]

24. Kim, H.Y.; Kim, H.; Gweon, D.G.; Jeong, J. Development of a novel spherical actuator with two degrees of freedom. IEEE/ASME Trans. Mechatron. 2014, 20, 532-540. [CrossRef]

25. Heya, A.; Hirata, K.; Ezaki, S.; Ota, T. Dynamic Analysis of a new three-degree-of-freedom actuator for image stabilization. IEEE Trans. Magn. 2017, 53, 8203004. [CrossRef]

26. Heya, A.; Hirata, K.; Niguchi, N. Dynamic modeling and control of three-degree-of-freedom electromagnetic actuator for image stabilization. IEEE Trans. Magn. 2018, 54, 8207905. [CrossRef]

27. Heya, A.; Hirata, K. Experimental verification of three-degree-of-freedom electromagnetic actuator for image stabilization. Sensors 2020, 20, 2485. [CrossRef] [PubMed]

28. Chu, J.; Niguchi, N.; Hirata, K. Design and analysis of a new spherical actuator. In Proceedings of the 2015 IEEE International Magnetics Conference (INTERMAG), Beijing, China, 11-15 May 2015; p. 1.

29. Fusayasu, H.; Masuyama, Y.; Hirata, K.; Niguchi, N.; Takahara, K. Analysis Accuracy in Positioning Calculation for Three-Degreeof-Freedom Spherical Actuator. IEEE Trans. Magn. 2021, 57, 8204104. [CrossRef]

30. Yan, L.; Chen, I.M.; Yang, G.; Lee, K.M. Analytical and experimental investigation on the magnetic field and torque of a permanent magnet spherical actuator. IEEE/ASME Trans. Mechatron. 2006, 11, 409-419. 